\title{
SYSTEMS-BASED APPROACH TO ENVIRONMENTAL INVESTMENT ANALYSIS BASED ON THE SERBIAN NATIONAL LIST OF ENVIRONMENTAL INDICATORS
}

\author{
Jelena Malenović-Nikolić*, \\ Dejan Krstić, \\ Biljana Matejević-Nikolić2 \\ Janko Čipev³, \\ Mina Krstić
}

${ }^{1}$ Faculty of Occupational Safety in Niš, Niš, Serbia

${ }^{2}$ The Faculty of Civil Engineering and Architecture,

Niš, Serbia

${ }^{3}$ Put Inženjering LLC, Niš,

Niš, Serbia

\begin{abstract}
:
Environmental science generally fosters an interdisciplinary approach within the scope of its studies, but specific issues require additional attention. Environmental pollution is studied within natural, social, and technical sciences, but the existence of environmental issues suggests that a more intensive cooperation between scientists from different fields is necessary. The use of a systems-based approach to the analysis of studies within environmental science should emphasize the need for a detailed determination of the causes of environmental quality degradation and the methods for its mitigation.
\end{abstract}

Keywords:

environmental indicators, energy, subjects of the system.

\section{INTRODUCTION}

Environmental issues are studies within numerous sciences, such as ecology, biology, physics, chemistry, botany, zoology, mineralogy, geology, geography, statistics, sociology, medicine, law, economics, politics, and so forth. Analysis of the current state and the causes of environmental pollution as well as the consequences to wildlife is performed in an integrated manner and within an interdisciplinary approach. Environmental science is studied in the form of environmental engineering studies, supported by social sciences. The goal is to provide a detailed analysis of the influence of biological, chemical, physical, material, and energy processes on climate change and the quality of basic environmental elements. A systematic analysis of environmental issues began as early as the 1960s, with the enactment of international protocols and environmental legislation. Environmental conservation activities are carried out daily, in compliance with the prescribed and adopted measures for the preservation of biological balance.

Ecology and environmental science are fairly similar but can by no means be terminologically equated. Ecology studies the distribution and range of living organisms and the biological interactions between them,
Correspondence:

Jelena Malenović-Nikolić

e-mail:

jelena.malenovic@znrfak.ni.ac.rs 
whereas environmental science mainly focuses on the interaction between living organisms and the environment. Ecology also takes an interdisciplinary approach, only as a branch of biology, following the principles of physics, chemistry, climatology, and geography. The environment is primarily studied in terms of pollution effects, using technical principles and knowledge related to environmental monitoring, spatial planning, statistics, information science, environmental quality indicators.

\section{ENVIRONMENTAL QUALITY INDICATORS}

The significance of environmental information and data was confirmed in 2003, at the Fifth Ministerial Conference "Environment for Europe" [1], held in Kiev, Ukraine. The conference emphasized the benefits of using indicators when defining policies and influencing public opinion to start resolving the environmental issues. It was concluded that mechanisms should be put in place to assess the environmental impact based on the relevant indicators. Global monitoring of the state of the environment is possible using indicators, which are adopted in accordance with national environmental policies, but also using general principles specific to global development.

Formation of internationally accepted environmental indicators and their use during the creation of national reports on the state of the environment represent significant progress for the monitoring of pollutant emission impact. Guidelines for indicator use are also very important because they have been developed by experts in environmental protection and statistics, hired by international organizations, academic institutions, and civil society associations.

Basic environmental indicators have been defined to allow easier monitoring of the basic elements [2], such as biochemical oxygen demand, biodiversity, climate change, ozone layer depletion, and cross-border emissions. Monitoring of specific pollutants is defined within indicator sets, which also prescribe the sampling methodology, the units used to present data, and the monitoring period. If the use of indicators is properly planned and based on a sufficient amount of time series data, it is possible to monitor changes and conduct a real assessment of the impact on the quality of basic environmental elements. The complexity of the set of national indicators can reveal a country's treatment of its healthcare and safe living conditions, as well as the financial possibilities to procure measuring equipment and to comply with international methodological recommendations.
Creation of the sets of indicators for sustainable development, environmental performance, or environmental quality is based on the indicators of environmental pressure, state, impact, and response. Identification and determination of indicator types is very important for the accomplishment of national and international environmental goals. A comparative analysis based on internationally recognized methods can contribute to data collection for the calculation of key indicators and the creation of an international database.

\subsection{SERBIAN NATIONAL LIST OF ENVIRONMENTAL INDICATORS}

In Serbia, monitoring of the state of the environment is performed using the National List of Environmental Indicators for the purpose of assessing the quality reduction of water, air, and soil, to inform the public, and to facilitate decision making pertaining to pollution mitigation.

The National List of Environmental Indicators [3] has been defined so as to allow an international comparative analysis of indicators. Yet, it should be noted that some countries in the region utilize more complex sets of indicators. EU members usually utilize more complex current state assessments, so it is impossible to compare all the parameters that are monitored in more developed countries.

Current state assessment and creation of the environmental assessment report are based on available data, so valid methodologies are implemented regardless of apparent deficiencies. Statistical data on environmental quality are publicly available and are publicized in a designated period, depending on the prescribed monitoring period. The report is created in accordance with international recommendations while adhering to the national legislation and the existing institutional mechanisms.

The Rulebook on the National List of Environmental Indicators ("Official Gazette of the Republic of Serbia", no. 37/2011) provides the general description of the indicators and classifies the indicators by subsections (pressures, state, impacts, influencing factors, and societal response) into topical sections. The General Description of Indicators elaborates on their [3]

1. national and international importance;

2. reporting relevance using a given indicator;

3. measurability and statistical adequacy;

4. simplicity and ease of understanding;

5. economic viability. 
The data in the National List of Indicators are categorized into the following topical sections [3]:

1. Air and climate change;

2. Water;

3. Nature and biodiversity;

4. Land;

5. Waste;

6. Noise;

7. Nonionizing radiation;

8. Forestry, hunting, and fishing;

9. Sustainable use of natural resources;

10. Economic and social potentials and environmentally-relevant activities;

11. International and national legislation, as well as measures (strategies, plans, programs, agreements), reports, and other documents and activities pertaining to environmental protection;

12. Subjects of the environmental protection system.

The area of study is all-encompassing, but the issue is the lack of finances to implement the established solutions.

\subsection{ECONOMIC POTENTIALS AND ENVIRONMENTALLY- RELEVANT ACTIVITIES}

The National List of Environmental Indicators, specifically topical section 10, Economic and social potentials and environmentally-relevant activities, defines 17 indicators across seven fields: chemicals and health; industry; energy industry; agriculture; transport; tourism; and urbanization [3].

The above presented indicators from the tenth topical section suggest that special emphasis is given to the analysis of impacts from the energy industry and agriculture.

With regard to subsections, the impact indicators comprise only [3] Total amount of particularly hazardous chemicals on the market (10.59), while the indicators of state express the growth of urban settlements using the surface area of urban settlements and their populations (Urban settlements - 10.75).

The societal response indicators comprise [3] Environmental management system (10.60), Share of recycling in the gross domestic product (10.61), Total energy intensity (10.64), Consumption of primary energy from renewable sources (10.65), Consumption of electrical energy from renewable sources (10.66), and Areas under organic agriculture (10.67).

\begin{tabular}{ll}
\hline \multicolumn{1}{c}{ Topical section: Economic and social potentials and environmentally-relevant activities } \\
\hline Chemicals and health & 10.59. Total amount of particularly hazardous chemicals on the market \\
\hline Industry & 10.60. Environmental management system \\
& 10.61. Share of recycling in the gross domestic product \\
\hline 10.62. Total consumption of primary energy by energy-generating product & 10.63. Final energy consumption by sector \\
10.64. Total energy intensity & 10.65. Consumption of primary energy from renewable sources \\
Energy industry & 10.66. Consumption of electrical energy from renewable sources \\
\hline 10.67. Areas under organic agriculture \\
10.68. Consumption of mineral fertilizers and plant protection products \\
10.69. Irrigation of arable surfaces \\
10.70. Agricultural areas of high natural value \\
10.71. Passenger and freight transport related to GDP \\
10.72. Consumption of fuels and cleaner and alternative fuels in transport \\
10.73. Motor vehicles \\
Transport & 10.74. Tourism intensity \\
\hline 10.75. Urban settlements
\end{tabular}

Table 1 - Economic and social potentials and environmentally-relevant activities [3] 
The following indicators are considered as influencing factors [3]: Total consumption of primary energy by energy-generating product (10.62), Final energy consumption by sector (10.63), Passenger and freight transport related to GDP (10.71), Consumption of fuels and cleaner and alternative fuels in transport (10.72), Motor vehicles (10.73), Tourism intensity (10.74), and Urban settlements (10.75). Consumption of mineral fertilizers and plant protection products (10.68), Irrigation of arable surfaces (10.69), Agricultural areas of high natural value (10.70), Tourism intensity (10.74), and Urban settlements (10.75) are categorized as pressure indicators.

\section{ENVIRONMENTAL QUALITY INDICATORS}

The twelfth topical section, Subjects of the environmental protection system, contains the following five indicators, all under societal reactions subsection: Budget expenditure (12.77), Investment and current expenditure (12.78), Income from fees and taxes (12.79), Resources for subsidies and other incentives (12.80), International financial aids (12.81).

The Serbian Environmental Protection Agency, operating within the Ministry of Environmental Protection, is tasked with creating the annual Report on the State of the Environment in the Republic of Serbia [4], pursuant to articles 76 and 77 of the Law on Environmental Protection ("Official Gazette of the Republic of Serbia", no. 135/04, 36/09, 36/09 - another law, 72/09 - another law, 43/11 - decision by the Constitutional Court, 14/2016 - decision by the Constitutional Court). The most recent report was published for the year 2018 and was written based on the data collected via the information system of environmental protection and through direct cooperation with the relevant institutions that collect data on the state of the environment [4].

The report is intended both for decision makers in the field of environmental protection and for the professional and general public [4], and it is thus directly compliant with Article 74 of the Serbian Constitution, which establishes the right of citizens to a healthy environment as well as to timely and complete information about its state. It is also indirectly observable from the report to what extent the environmental policy aims have been achieved and measures implemented, as defined in several strategic and planning documents (National Environmental Protection Program ("Official Gazette of the Republic of Serbia”, no. 12/10), National Sustainable Development Strategy ("Official Gazette of the Republic of Serbia”, no. 57/08), and National Strategy for Sustainable Use of Natural Resources and Assets ("Official Gazette of the Republic of Serbia", no. 33/12)) [4].

The report on the state of the environment is based on the indicators presented by topical section in the National List of Environmental Indicators.

The report data (Figure 1) show that budget expenditure for environmental protection amounts to only $0.3 \%$ of the GDP annually.

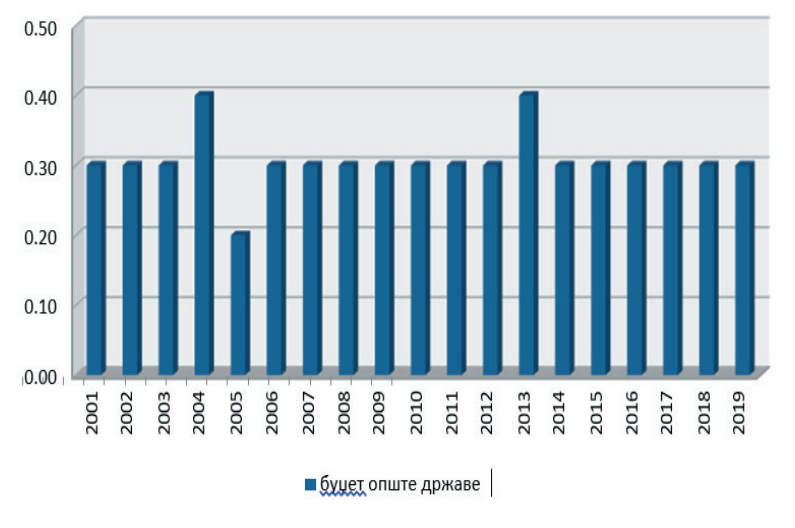

Figure 1 - Budget expenditure, \% GDP [4]

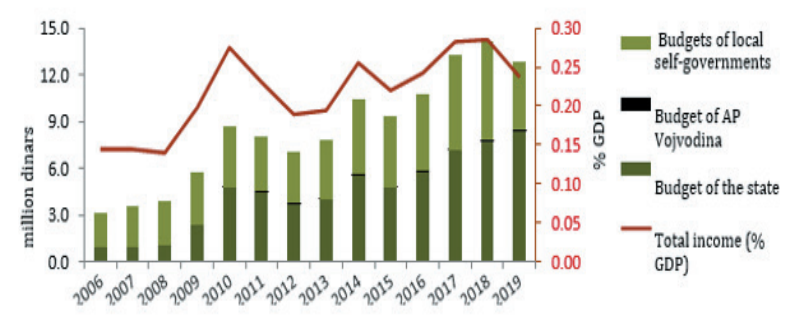

Figure 2 - Income from fees and taxes for environmental protection and improvement, \% GDP [4]

The total income from environmental fees and taxes (Figure 2) has grown steadily from 2015 until 2019, when it dropped to $0.24 \%$ of the GDP.

The largest share of the income from fees comes from fees for emissions of sulphur dioxide, nitrogen dioxide, powder materials, and deposited waste $(6.27$ billion dinars), for products that become special waste streams after use (4.39 billion dinars), and for wildlife trade ( 1.78 billion dinars). 
The analysis of income from environmental taxes shows that energy industry has the largest share of $85 \%$ (Figures 3 and 4).

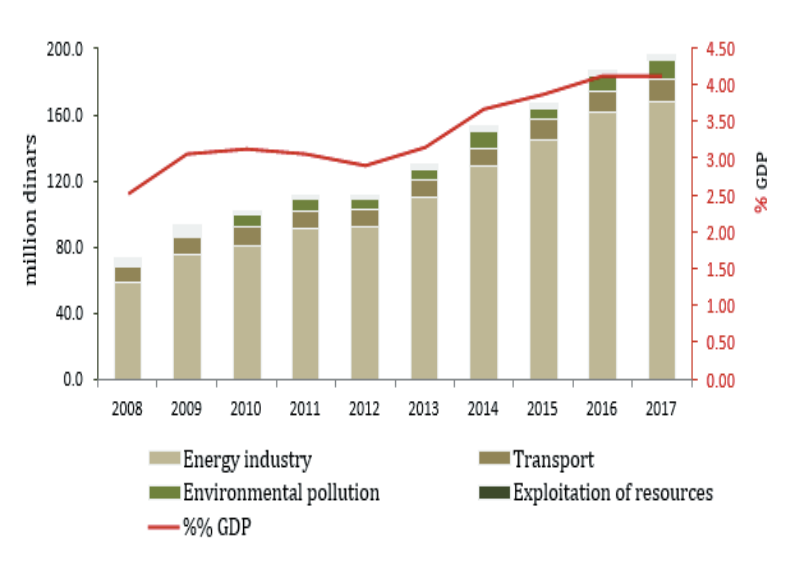

Figure 3 - Income from environmental taxes,

$$
\% \text { GDP [4] }
$$

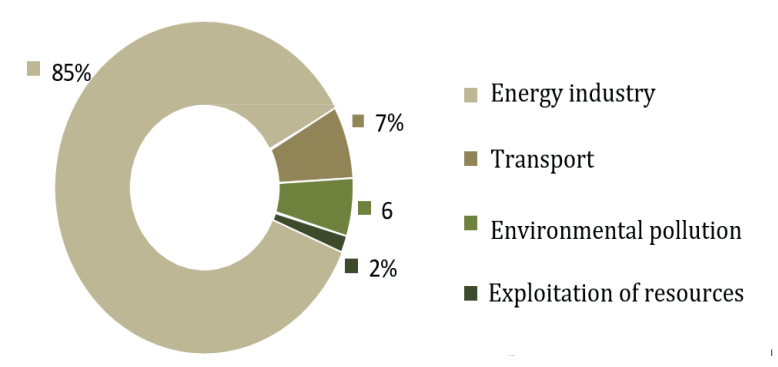

Figure 4 - Sources of environmental tax income [4]

Environmental investments from the economy sector are also very small (Figure 5) and amount to $0.05 \%$ of the GDP (2.96 billion dinars), with the largest share coming from energy industry and mining $(85.9 \%)$, followed by industry in general (7.9\%). The allocated resources for subsidies (Figure 6) have been estimated at $0.08 \%$ of the GDP (5.15 billion dinars), with the recycling industry being the largest recipient of these resources (79.9\%).

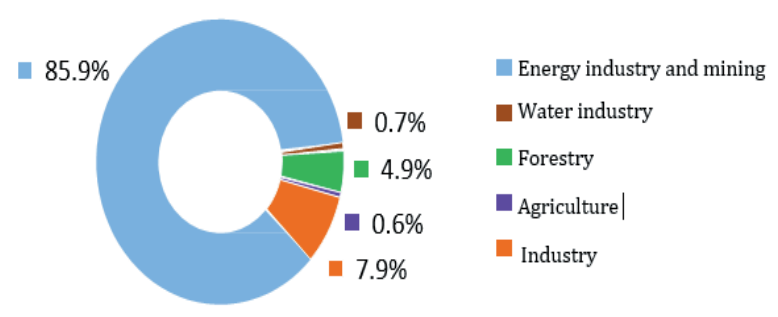

Figure 5 - Sources of investment from the economy sector [4]

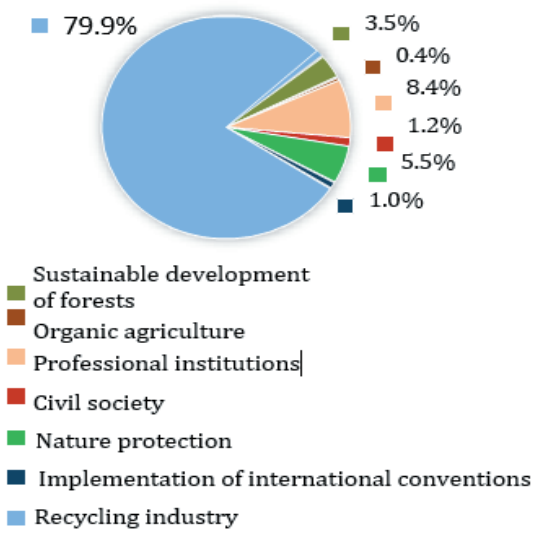

Figure 6 - Allocated resources and target areas [4]

Financial incentives from the state concerning the environment are shown in Figure 7.

1-Total (million dinars), 2-\% GDP

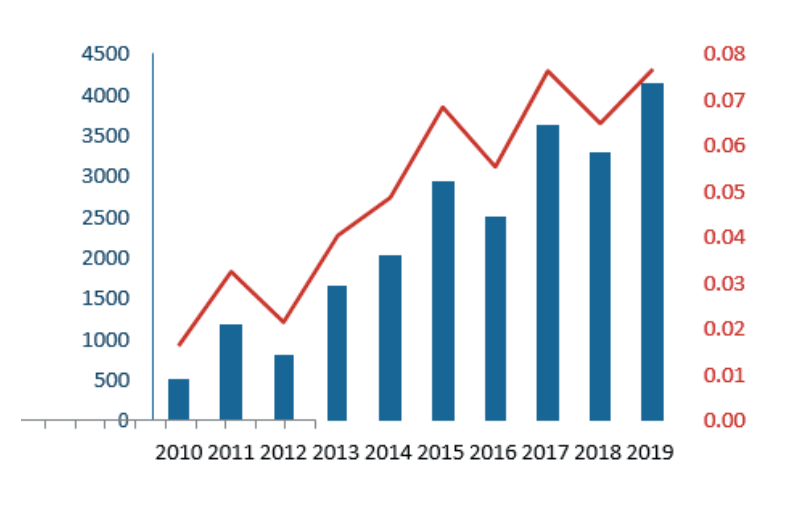

Figure 7 - Financial incentives from the state, million dinars and -\% GDP [4]

It is also important to emphasize that international donations for the sectors Environmental Protection and Water Supply and Waste Management (Figure 8) amount to $0.08 \%$ of the GDP ( 4.6 billion dinars), with the biggest donations coming from Germany, Sweden, and the EU. 


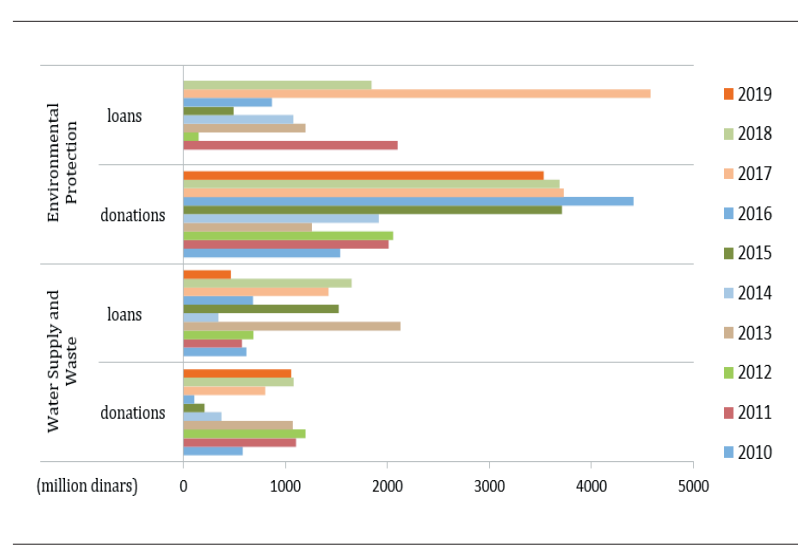

Figure 8 - International financial aids - donations and loans for the sectors Environmental Protection and Water Supply and Waste Management [4]

In 2019, the biggest donors for the Environmental Protection sector were the EU with 1.9 billion dinars, Germany with 1.1 billion dinars, and Sweden with 448 million dinars [4]. The total amount of financial resources for investments and current expenditure is $0.72 \%$ of the GDP.

\section{CONCLUSION}

The data presented in the paper indicate that environmental investments are rather small in relation to the GDP, which makes it impossible to maintain the quality of basic environmental elements at a satisfactory level, regardless of scientific development and achievements. It is essential to regularly conduct environmental monitoring and publish reports that depict the actual state.

The real picture of investment in a healthy environment at the national level can only be obtained based on the indicators such as subjects of the environmental protection system and based on the use of relevant data and information derived from the official data by state institutions, scientific and professional organizations, and other involved parties. A systems-based approach to the analysis of environmental issues provides a good foundation for grasping the situation and making comparisons against environmental investments in other countries.

\section{ACKNOWLEDGEMENTS}

This research is financed by the Ministry of Education, Science and Technological Development of the Republic of Serbia.

\section{REFERENCES}

[1] J. Aleksić i G. Dražić, Applied Ecology, Belgrade: Ministry of Agriculture and Enviromental Protection, 2014.

[2] M. Kokin i I. Atamuradova, Environmental Indicators and Indicators-based Assessment Reports Eastern Europe, Caucasus and Central Asia, Economic Commission for Europe, 2007.

[3] Official Gazette of the Republic of Serbia, Rulebook on the National List of Environmental Indicators, Vols. 37, 2011, Belgrade: Ministry of the Environment, 2011.

[4] F. Radović, D. Lekić i T. Perunović, Report on the State of the Environment in the Republic of Serbia for 2019., Belgrade: Ministry of Environmental Protection of the Republic of Serbia, 2019. 